\title{
Italian Cuisine: Characteristics and Effects
}

\section{Ayşe Nevin SERT}

Selçuk University, Konya, Turkey.

nevinsert@gmail.com

\begin{abstract}
It is suggested that today's kitchens seem to interact with each other in the historical process. Italian cuisine is one of the most well-known cuisines of Europe and interacts with a wide variety of cuisines. The effect of the outstanding Italian cuisine with regional diversity can be seen in many kitchens. In this study the historical development of the Italian cuisine is discussed. Regional richness of Italian cuisine and the reasons for this wealth is examined. Also the products that the Italian cuisine introduced to the world are stated.
\end{abstract}

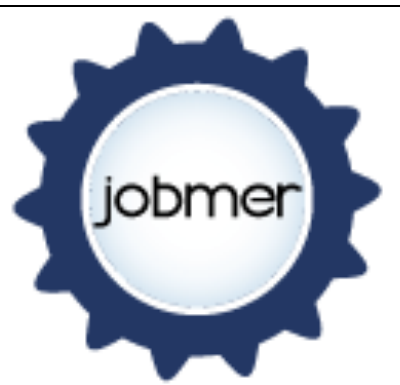

Journal of Business

Management and Economic Research

Vol.1, Issue.1, 2017

pp.49y 57

Keywords: Italian Cuisine, Pizza, Pasta, Coffee.

Doi: $10.29226 /$ jobmer.2017.4

\section{Suggested Citation:}

Sert, A. N., (2017) Italian Cuisine: Characteristics and Effects, Journal of Business Management and Economic Research, Vo.1, Issue.1, pp.49-57 


\section{Introduction}

The roots of the Italian cuisine, that is one of the oldest cuisines in Europe, are based on the heritage of ancient cultures. The Italian cuisine was influenced by the civilizations that invaded Italy. The influence of Ancient Greece and Etruscans is still felt today (Volpi, 2003). The Etruscans' farming methods, the Romans, Phoenicians, the Goths, the Normanians, the French, the Spaniards, the Arabs and the Austrians, who had invaded the country, influenced this cuisine (Sarış̧ık, 2014). Nowadays, considering how much pizza and pasta are loved and widely used, it is seen that Italian cuisine also influences other cuisine as well.

The geographical location and climate of Italy influenced the culinary culture. Products such as wheat, grapes, wine, olives, olive oil, corn, rice, sugar beet, tobacco, soybean, sunflower, potatoes, tomatoes, apples, pears, peaches, oranges, lemons and mandarins are produced in Italy where the Mediterranean climate dominates. In addition, olive oil, wine and cheese are some of the most important and widely used products identified with Italian traditions. Italian cuisine shows great differences by regions. In Italy it is possible to talk about different culinary styles belonging to each region. Local traditions and customs consist of the long and complex historical developments, and local habits influenced by these developments. Beside in Italy, significant and the rooted values of cultural and social differences continue to exist today, while mass marketing try to equalize the differences.

\section{Feature and Effects of Italian Cuisines}

Italy is a country with hundreds of cities, thousands of bell-towers and hundreds of recipes. Mirroring a history shaped by political divisions, provincial commitment and a wide range of gastronomic traditions makes Italian cuisine heritage so rich and appealing today than all the other countries. This attractiveness is due to the fact that the Italian cuisine is very rich in terms of regional diversity (Capatti ve Montanari, 2003). As it is stated by Belge (2001) "Italian dishes" is actually an abstraction, and according to Italians, there is no single Italian dishes, on the contrary there are Florence, Genova, Milano, Naples, Sicily and so on dishes (David, 1999). It may suggested that the reason for this diversity is due largely to the geographical structure and history of Italy.

Italy is separated from European continent by the highest mountain range of Europe, and in this narrow country the mountains stretch from north to south. This has led to the formation of regions with different geographical characteristics. In the country, on one side, fertile valleys, mountains covered with forests, bare rocks, arid plains and on the other side is the Mediterranean coast. Different climates resulting from the geographical situation have created unique geographical and historical areas. Nevertheless, this geographical diversity alone is insufficient to explain the richness of the culinary culture. In order to explain the richness and diversity in the culinary culture, it is necessary to look at the history as well. Instead of central authority, there were dukes, princes, small kingdoms and states that could not get along well in the country. The political union was not formed until 1861. However, for the last three thousand years, it has been occupied by many nation and civilizations. Many of them had added something from their own culture. The influences of the Etruscans and the Ancient Greeks, who were the hosts, are still felt. Central authority was not established in the Middle Ages and instead there were strong and free city states. In these cities, which were very advanced in the arts and trade, different culinary cultures had developed. After the collapse of these city-states, Northern Italy was occasionally invaded by France and Austria, and their cuisine were influenced by this invading. The wealthiness of the northern Italian cities created the "fresh pasta" culture. Fresh pasta is made with eggs, cheese, cream and other expensive materials. It is no coincidence that Bologno in the north is Italy's gastronomic capital. Florence has been enriched since the 13th century. A very wealthy 
trader family the Medici dominated Florence, supported art and accelerated the Renaissance. Renaissance effected many field and made the revolution in art and mirror it to culinary culture as well. Thereby a richer food culture had been formed in Italy (Capatti ve Montanari ,2003).

While there were many independent cities in the north, the situation in the south was different. The south lived as united for long time. The South, separated from northern Europe by major trade routes, is isolated and living in poverty. People in the South had tried to do the best with what they had in their hands. For example spaghetti and pizza whose homeland is Sought, was born as a food for poor people and spreading around the world with Italian immigrants and became very popular. Another one of the greatest contributions South has made to Italian cuisine is "dry pasta". Dry pasta is suitable for hiding, selling, and transporting, and in Sicily in Naples it has been popular since the Arabian invasion in 1700s, and from there it spread to the world. The south was occupied by different civilizations at different times and all of them had different effects. The Muslims who remained here for two centuries had the greatest effect. Muslims have influenced Western culinary culture with rice, oranges, lemons, peaches, sugar and more. This effect is still strong in the south, especially in Sicily (Volpi, 2003).

When comes back further, it is seen that taking advantage of ancient Greek traditions, the Romans have improved Italian culinary cultures. Before the Romans, the food is supposed to be quite salty because of the necessity of the food conservator. It is also estimated that they were not very fresh. For the purpose of hiding these unpleasant tastes, the Romans added honey, sweet wine, dried fruit and vinegar to the fish and meat. They also tried to change the smell of food by adding musk, amber, pepper and coriander. The situation was similar for all Europe till the 19th century, when the rapid transport developed and the food did not need to be salted and preserved to a great extent. Roman flavour in Italy manifests itself in the bagrodolce or the sweet-sour sauces that Italians like to use in wild boar, rabbit and deer. With the Renaissance in the 15th century, interest in classical cooking methods had increased again. The first book about culinary culture containing recipes of Maestro Martino is the book titled "Platina de honest voluptate et valetudine vulgare" which was prepared by Bartolomeo Sacchi in 1474. Twenty years later, the book of Apicius written by Marcus Apicius was published. Apicius has taken the information in his book from the ancient Greek cuisine. In fact, the notes of Apicius were lost and the book is estimated to be compiled from the notes of a student of him (David, 1999).

In 1533, Catherine who was an Italian noblewoman from the Medici family married with the prince of France II. Henri. This marriage was the beginning of the influence of Italian cuisine on the European cuisine. When she went to Paris, Catherine took her new vegetables, Italian culinary arts and table layout with herself. Thus she brought her Italian culinary art to France (Sarışık, 2014). In fact, this influence began in the previous century with the king of France VIII. Charles (1483-1498) and Catherine's father-in-law I. Francois. During the unsuccessful expedition to invade Napoli in 1495, I. François brought gardeners from Italy to France for raising green vegetables, cauliflower, spinach, artichokes and other vegetables. This effect of the Italian cuisine continued increased in the 1600s when Maria, the second bride from the Medici family married with France King IV. Henri and became the Queen. Such that the Venetian chronicler Zanetti complained about mixing everything with spices, sauces and herb and being garlic and onions in all the plates (Parasecoli, 2004).

During the periods when imports and exports are not improving, in London or Paris it was possible to find the best of everything which England or France produces. In Italy the best fish is actually to be eaten on the cost, the finest Parmesan cheese in and around Parma, the tenderest beef in Tuscany, where the cattle are raised (David, 1999). With the discovery of the 
New World in the 18th century, the Italian cuisine has been altered and enriched by the arrival of potatoes, tomatoes, peppers and corn which are known as the basis of Italian cuisine (Del Conte, 2001). Because of the poverty experienced in 19th and early 20th centuries, peasant and factory workers had an unchanging diet habits based on corn, rice, chestnuts, potatoes, legumes, a little greenery, and at least a diluted wine. In fact, all parts of society were affected by this poverty. Foods that were considered "heavy" were the foods traditionally consumed by the lower classes because their high calories and cheapness. For example, the beans were known as poor meat. Chestnut flour was used instead of wheat flour (Helstosk, 2008).

\section{Characteristics of Italian Cuisine}

With the discovery of America, potatoes and red peppers entered in to Italian kitchens and this made important changes. The Italian cuisine is very simple one. Although many meals consist of four to eight ingredients, this cuisine is very famous in the world. However regional differences are evident and almost every city has its own flavours (Capatti ve Montanari, 2003). For example, in Bologna the mortadella sauce, in Florence the bistecca alla Fiorentina steak cooked in wood fire is famous. Flavours and dishes vary according to the season. Each season has its own unique dishes. The ones cooked in the winter is Lombardi's polenta pasticciata, Bologno's lasagne verdi al forno and Veneto's brown bean soup. After Easter, lighter foods are preferred and Pastry in brood and crostini which is fried bread with anchovies and cheese are popular. In summer, all in Italy, vitello tonnato that is the cold veal with tuna fish sauce is widespread. Another point is the food names are a bit confusing. For example, the same pasta is named tagliolini in Florence, trenette in Genoa, and tonnarelli in Rome.

The Italian cuisine has an international reputation for its rich and varied Italian pizzeria and pastry and for other products. Some reasons for this recognition are as follows (Meiselman, 2009):

- The contribution of the country to the culinary arts and gastronomy,

- The international recognition of some typical Italian dishes (pizza, pasta etc.),

- Contrary to many other modern countries, the preservation of regional and local gastronomic traditions and customs in Italy,

- Compared to other European countries, in Italy, the characteristic of dishes has not changed much over the last 60 years,

- For Italians, eating is a social and enjoyable activity.

Various vegetables, plants and cheeses alongside pizza and pasta has also influenced the reputation and acceptance of Italian cuisine. Fish, olive oil, coffee, ice cream and tiramisu can also be added to this list.

- Some plants used in Italian cuisine are stated here (Davis, 1999).

Basil: It is popular in the South and used in tomato sauces, salads and soups, especially in the Genoa Pesto.

Mint: Widely used. It is used with meat, chicken, salad, sauce and desserts.

Marjoram: It is used in soup, dessert, stew and fish. Wild marjoram is also used in the Napolitana pizza. Sweet marjoram can be used instead of oregano, and in Italy goes into soup, stews, and fish dishes.

Celery: It is mainly used in vegetable soups. It is rarely served raw, possibly because it appears to be mostly of a rather stringy and thin growth.

Daphne: It is used in soups. 
Sage: It is widely used in Italian cuisine, especially with veal and calf's liver.

Garlic: According to David (1999), it is a mistake to suppose that all Italian dishes are heavily garlic flavoured. In the South, especially in Naples, garlics are used with the tomato sauce and fish soups. Spaghetti with oil and garlic is much beloved of the Neapolitants.

Potatoes: Significant changes occurred with the discovery of the New World and the introduction of potatoes, tomatoes, bell peppers and corn, which are known to be the basis of today's Italian cuisine but which had not been brought to the masses until the 18th century (Del Conte, 2001). However, wheat, corn, rice, potatoes, tomatoes as well as zucchini, eggplant pepper, artichokes, etc. are farmed in Italy, have a Mediterranean climate feature. As fruit, apples, pears, peaches, grapes, citrus fruits etc. are produced (Capatti ve Montanari, 2003).

- Cheeses in Italian Cuisine (David, 1999) :

Mozzarella: It can be used on all kinds of pastries.

Parmaggiano: It is also can be used on all kinds of pastries as well.

Ricotta: Fresh must be consumed. When it is choped and mixed with spinach, gnocchi is made. It is also used in the desserts.

Mascarpone: Used in all desserts.

Bel paese: Blue mould cheese.

Provoloni, pecorino: These cheeses becoming spicy when they are getting dry up.

- Olive oil

Mediterranean is an olive and olive oil paradise. According to Belge (2001), the best olives are produced in Italy. It is put forward that especially Tuscany and Abruzzi olive oil is very good (www. italiafoodforever). The colour of this olive oil is green and its consistency is dark (Belge, 2001). The first olive grove in Italy was planted in southern Italy in 1000 BC. Due to the commercial value of the olive oil, the Romans made the olive cultivation in all Italy in a short time. In $1500 \mathrm{AD}$, with the Medici family giving lands to the families who want to grow olives, all Tuscany was covered with olive trees (www. italiafoodforever). Olive oil is indispensable for Italian cuisine. Olive oil that is seen as a cooking tool and as a condiment and flavouring, is used in various forms (Whiteman, 2000).

- Coffee

Coffee is the most preferred hot drink in Italy. The special Italian coffees are widely used in the world. The espresso coffee which is a thick and hard, is identified with Italy. It is made of a special machine. Cappuccino is made from espresso, hot milk and milk foam made from steam (Morris, 2010).

- Ice cream

Ice cream is an important contribution Sicily made to the world. Sicilians made the first "ice cream" by carrying the ice down the mountains (Belge, 2001).

\section{- Tiramisu}

It was last added to the traditional Italian cuisine. It was first made in the town of Treviso in northern Italy in the 1970s and became a world famous dessert within 10 years. Tiramisu is made of sugar, eggs, sweet wine, mascarpone cheese and espresso coffee. It is served cold (Volpi, 2003). 
- The Fish

The fish is very important for the Italian cuisine and thus there are various fish dishes. Some of them are Pesce Spada Agghiotta, Guazzetto di Crostacei, Cape Sante alla Veneziana, Pesce all’ Acqua Pazza and Baccala' alla Romana (Volpi, 2003).

Pesce Spada Agghiotta: It is a stew made of the fish and shellfish.

Cape Sante alla Veneziana: It is a typical dish of the Venetian region. It is made of clam. Clams are found a lot in the Adriatic Sea.

Pesce all' Acqua Pazza: This dish is an old recipe that belongs to old fishermen in the Naples region. In the 1960s, it became popular on the luxury tourist attraction Capri island. The fish must be fresh. It is made of parsley, garlic, tomatoes, lemon, white meat and olive oil.

Baccala' alla Romana: Baccala is salted and dried morino fish imported from Norway. It's called as a food for poor. It is a favourite dish for those who cannot get fresh fish or live away from the sea. This fish steep in water for one day before cooking and during that time the water is changed several times.

Pizza

The pizza is cosmopolitan as it is consumed all over the world. The physical and linguistic similarity between pizza and lahmacun (meat dough), pizza and pide shows that there are many cultural influences in the Eastern Mediterranean, probably from east to west. In the Mediterranean, yeast and unleavened bread were made. The pizza was made as flatbread like pide. The ancient pizzas were little cakes made from a mixture of flour, water and olive oil, baked on a stone and topped with more oil, honey or herbs, and sometimes with a rich sauce. In Italy the Etruscans made bread that was seasoned with toppings then used to sop up gravy or soup. The ancient Greeks baked the toppings directly onto bread itself and resulting bread, called as plakuntos, took the place of a main course. The Ancient Romans united both the Ancient Greek and Etruscan pizzas and combined sweet with savoury toppings. Roman placenta was a pie made from wheat flour, topped with cheese mixed with honey, bay leaves and oil. As the Roman Empire spread across to Italy and Europe, they also made practise of making and eating these topped breads. These ancient flatbread can be called "pizzas" as it is embodied the basic concept of having one's meal on an edible plate or using one's bread as a plate and utensil. This flatbread (pizzas) was used as a plate because it's convenient for mobility and economic necessity. In short this ancient flatbread could be consider as precursors to the pizza as it topped with mushrooms, herbs or sauces. It is suggest that pizza is a word used by ancient Greeks, Arabs or Hebrews for pide, and others suggest that it came from Latin word picea, meaning 'of pitch', a term which may have referred to the texture or colour of baked bread or the bottom of the ancient pizza (Helstosky, 2008). In the middle ages the Italians ate flatbread or focaccia with whatever toppings they could get their hands on such as salt, herbs, olive oil, mushrooms, rarely some fish and meat. They also made the torta that is the most similar to the current pizza. Torta was consumed by all social classes in middle ages. During the Renaissance, the cooks began serving the torta with an edible crust. Like so many other Italian culinary specialities, the torta, and later the pizza relied on ease of preparation, a variety of flavours and the blending of only a few ingredients, either within or on top of the crust (David, 1999; Helstosky, 2008).

In the 1790s, the word "pizza" was used for a thin flatbread topped with various materials. Over the time the nobles also discovered this flavour. According to the anecdotes, some of the Neapolitan Bourbon kings secretly employed pizzeria in spite of their chef. Even II. Ferdinando, ordered to be made a special pizza oven in the palace. But, pizza had failed to 


\section{Journal of Business Management and Economic Research}

enter the daily food menu of nobles. The Neapolitans claim that this is because of Ferinando's Austrian mother, Mana Carolina as she put a tough reaction on the efforts of her husband and son of making the pizza a palace dish. The one of the reason Mona Carolina resisted the pizza was that she believed it was not suitable for ceremonial dishes in the palace. Actually for pizza, neither plate nor fork was being used, it was eaten by hand. However this food was ideal for bakers as no special saloon needed to be settled by the customers. The little space was enough for an oven and pizzas' dough. Also pizzas could be sold by street vendors like bagel (simit) (www.pizzatat.com).

Today, almost every pizza shop in the world has the "Margarita" pizza on its menu. This pizza was named after the Queen Margarita who was the king II. Vittorio Emanuele wife's. One day, a pizza contest was held and the Queen would choose the best pizza. Because of its resembles the Italian flag with its tomatoes and green peppers on white mozzarella cheese, the Queen chose this pizza. Since then, this pizza has been called as Margarita, the queen's name (Belge, 2001). For the most part, ancient and medieval pizzas relied on local materials and were produced locally. However, today's pizzas consist of a global mix. Wheat comes from the Middle East, olive oil and oregano from the Mediterranean, tomatoes from South America, basil from India, the water buffalo (used to make mozzarella cheese) come from Asia (Helstosky,2008).

It was not thanks to Italy that the pizza was spreading all over the world and reaching all cultures. Pizza knocked the doors of other cultures in a very different country. This country was America. Millions of Italians, mostly from the south, migrated to America in the 19th century and pasta and pizza were important elements that reminded them of their homeland. The first pizzeria opened in New York in 1895. Their first customers were Italian-Americans. This crunchy pita was a very filling meal for Italian workers and also attracted the attention of business colleagues from other cultures (www.pizzatat.com).

The word "pasta" comes from the Italian word "maccarruni" which means "made into a dough by force". In Italian language maccarruni (macaroni) called as "pasta". The word of pasta is used for dishes whose main ingredients is pasta. Pasta is available in hundreds of different shapes and local names. Especially in southern Italy, pasta is consumed very much and eaten in the accompaniment of rich sauces prepared. There are two theories about the birth of the Italian pasta, which are made in two forms, dry and fresh. The first theory is the "nationalist". This theory bases the pasta on the Etruscans. It is claimed that some of the tools found in the Etruscan graves were used for making pasta. The other theory suggests that Marco Polo brought the pasta from China (Belge, 2001). On the side, although it was said that the noodle that would become the national dish of Sicily and southern Italy, was brought by Arabs during the wars of the 9th century, it is believed that the cooking the pasta-type pastries, both fresh and dry, was well known in Greek and Roman times. However, those who developed the dried pastry types in the 9th century, were probably Arabs. There is also a mention of "bariscella plena de macaronis" in a Genoa warehouse dated 1279. According to the information given by geographer Al-Idrisi (1099-1166), the first real dry pasta (pasta secca) named "itrija" from Trabia near Palermo was made in 12th century that was at least a century before Marco Polo and it was sent from there to the other countries with the ships.

Dry pasta is made from durum (hard) wheat. Durum wheat is important in terms of better protection of texture and taste when it is cooked compared to soft wheat and preventing the raw pasta from breaking down. (Tez, 2012). Dry pasta can last for a long time but fresh pasta should be consumed immediately. At the end of the Middle Ages, the pasta began to evolve to its present state. The tomato pasta's best friend, was brought to Italy by the Spaniards, and it was seen to have been grown in Siena and Napoli in about 1600s. It was initially used as an ornamental plant, with high curiosity value, than a source of food. Tomato began to 
become popular in the 18th century. Pasta was not an important meal in Neapolitan diet until the 17th century and tomato sauce did not become fashionable for another hundred years. In the 19th century, political unification in Italy occurred, but strong regional differences remained unchanged. Like almost everything else in Italian, the forms and shapes of pasta have strictly local origins (Alexander, 2000).

Some of them are: like long lasagna Mafelde with curved edges, narrow or medium thickness Nocchette refers to a small "bow-ties", a stuffed pasta forming a triangle shape Pansotti, radiator-like, rectangular and grille-shaped Radiatori, small, flat square Quadrettini, large tube cut into slices, Zitti. Fettuccine is a macaroni cut into flat strips, coloured green with spinach, little rings Anellini, wheel-shaped Ruote. Bigol is the larger type of spaghetti; in small tube shape Tubettini. Pasta with international recognition are: Farfalle in the form of a butterfly or bow tie. Lasagne are wide, flat-shaped, jagged edges pasta, and possibly one of the oldest types of pasta. Linguine is long thin flat pieces of pasta. Thin, long, curly Fusilli, also known as twisted pasta; diagonal cut tubular Penne; small square shaped Ravioli filled with varied stuffing such as full of mince, spinach or cheese. Tortellini is small rounds of pasta, filled, as with a meat or cheese stuffing, and then shaped into rings (Sarışık, 2014).

\section{Conclusion}

Italian cuisine is a rich cuisine that varies from region to region. The Italian cuisine, which has been influenced by Etruscan, Ancient Greek, Ancient Roman, Byzantine and Arabic cuisines, has developed with the history and, social and political changes for many years. Today it is known and loved all over the world. Food and dishes and the supplies used for cooking are vary by region. Many of the main dishes of the national cuisine were originally local, then spread all over Italy. There had been some changes during this expansion. Pizza and pasta are essential for the Italian cuisine. In addition to pizza and pasta, cheese and wine make up a large portion of the cuisine with many varieties. Coffee, and especially espresso, is one of the important elements of the Italian cuisine (Volpi, 2003). The distinction could be made between rich and poor cuisine in Italian cuisine. The poor cuisine is only aimed at feeding and at this point it is difficult to talk about the cuisine art.

Unlike England, Germany and the United States, when wealth and urbanization increased in Italy, the fast food was not in demand and the interest in traditional meals and small-scale food producers had increased. Home-made meals continued to occupy an important place in the Italian cuisine (Helstosky, 2008). The Italian cuisine has now become a heritage that all Italians have carefully guarded and is trying to be protected from globalization. Unlike European neighbours, Italian cuisine is resisting fast food restaurants (Helstosky, 2004). 


\section{References}

Alexander, D. (2000). The Geography of Italian Pasta, The Professional Geographer, 52(3), 553-566.

Belge, M. (2001). Yemek Kültürü, İstanbul: İletişi Yayınları.

Capatti, A.and Montanari, M. (2003). Italian Cuisine: A Cultural History,New York: Colombia University Pres.

David, E. (1999). Italian Food, U.S.A: Penguin Books.

Del Conte, A. (2001). Gastronomy of Italy, New York: Friedman/Fairman.

Helstosky, C. (2004). Garlic \& Oil. Politics and Food in Italy. New York: BERG.

Helstosky, C.(2008). Pizza: A Global History, London: Reaktion Boks.

Meiselman, H.L. (2009). Meals in science and practice, UK: Woodhead.

Morris, J. (2010). Making Italian Espresso, Making Espresso Italian. Food \& History, 8(2), 155-184.

Parasecoli, F. (2004). Food Culture in Italy, London: Greenwood Press.

Sarışık, M. (2014). Uluslar arası Gastronomi, Ankara: Detay Yayıncılık.

Tez, Z. (2012). Lezzetin Tarihi: Geçmişten Bugüne Yiyecek, İçecek ve Keyif Vericiler, İstanbul: Hayy Kitap.

Volpi, A.M. (2003). The Timeless Art of Italian Cuisine, Italiy: Palation Inc.

Whiteman, K. (2000). A Cook's Guide to Italian Ingredients, UK: Hermes House.

http://www.pizzatat.com/services-32-32-Pizzanin_Tarihcesi.html

http://www.italianfoodforever.com/2011/10/olive-oil-liquid-gold/ 